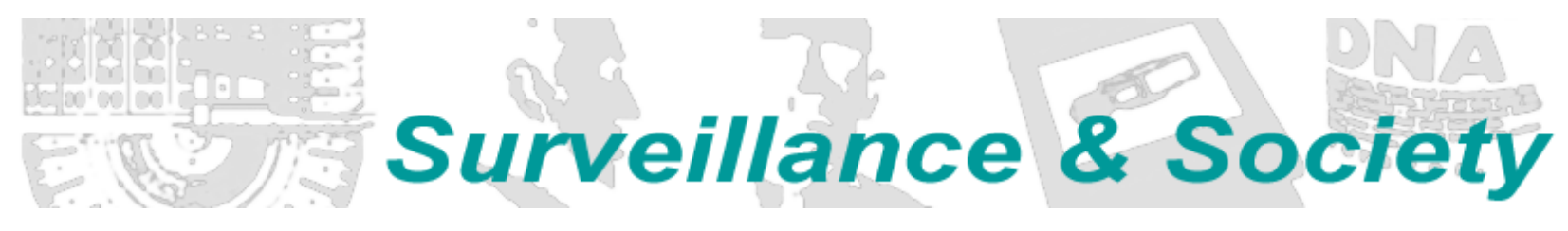

\title{
Essay $\quad$ The Field of Vegetable Operations
}

\section{Henry Neim Osman}

Brown University, USA

henry_osman@,brown.edu

Leaf litter crunched under Sam's feet while the May sun, already hot, streamed through. The canopy was cluttered, old Hemlocks fighting against Mimosas and Tree-of-Heavens, a tree toxic to its neighbors but whose presence didn't seem to cut through the forest's disturbed chaos. Summer had come early this year, and he wanted to wash away the sweet stink of new growth and the heat built up under his skin. He had read about a swimming hole online and pinned its location in his maps app. But his service had cut out a mile into the forest, so he decided to follow his senses and belief in an imagined ability to find water, primal and programmed deep in his bones; he wandered off the trail.

At this exact moment, Sam thought about how he was usually a responsible hiker, one who followed the path and never littered. But earlier that day, the trail had been crowded; families bringing their kids out of the city, a man in all Adidas with one of those big Hungarian dogs that looked like walking mops and was already covered in broken twigs. Someone even had one of those bionic dogs, covered in fake fur with glassy lens-eyes, programmed to pant but still dependent upon a battery charge. Didn't Sam come here to be alone, away from work (data entry) and home, a few hours when he could be in his head but be in his head in nature? Skinny dip in a swimming hole, sight unseen? He then imagined himself running through the woods, lit up in green. His daydream adopted the look of a 2000's trance video, as if the forest itself contained a rhythm, some four-on-the-floor beat that thumped with every step. Were crowds of dancers about to emerge from the trees, was the set about to change - maybe to a Greek island, him on a jet ski? His vision shifted as he rose above the dancers and the ocean like the eye of an angel when suddenly (in the middle of the air!) his foot hit a boulder and he tumbled back down onto the forest floor. A ravine: rocks and mulch and decomposed matter filled his nose as he was beached, gasping.

Sam looked up for a minute as he tried to remember what happened (why couldn't he just be present, smell the earth and the leaves and not plot out music videos and dance breaks for songs that would never exist?). Nothing was broken but for a rip down the side of his shirt, an old striped tee an ex had left in his closet. As he stood up, he noticed he was in a pile of now-crushed groundcover, some spinach or lambs-quarters or pigweed or whatever species was now growing here. After brushing off debris and putting his hat back on, he realized he was close to that swimming hole. He turned and heard a flicker. There hadn't been many insects in the woods that day - there were less and less every year but sometimes, during spring, clouds of no-see-ums might return.

A metallic buzz rang through the forest, omnipresent enough that he couldn't pinpoint where it was coming from. He wondered if he saw a shimmer in the distance, the sun catching on something impossibly bright in the canopy, or if it was just the impact from his fall. To his right, hovering next to a tulip tree, was a matte- 
green robotic bee, eyes aglow and biomimetic wings rapidly flapping, a presence that Sam's eyes passed over.

MetaBee \#21783

The nanobionic spinach lit up in fluorescent shades, yellows and greens and whites, bursts of orange. Almost like the deep ocean, bioluminescent schools of fish, organisms that escape taxonomy, the clouds of algae that flash in and out of existence. Now you see, now you don't, lithe bodies that expand into quivering blobs as they rise in the water column. A metallic flitter shot between two trees. An insectoid body whose wings were moving so fast they were almost a blur. The MetaBee ${ }^{T M}$ \#21783's iridescent compound eyes, each composed of 180 ommatidia, took in the psychedelic registers of machine vision that extend far beyond the range of the human. To MetaBee ${ }^{T M}$ \#21783's eyes, sixteen spinach leaves flashed yellow (signaling that movement was detected, with leaves sustaining damage); four went green (due to the presence of near range RFID); seven were orange (their roots had sensed nitroaromatic compounds [gunpowder, landmines, bomb residue] in the soil, but MetaBee ${ }^{T M} \# 21783$ had seen these sensors triggered hours before).

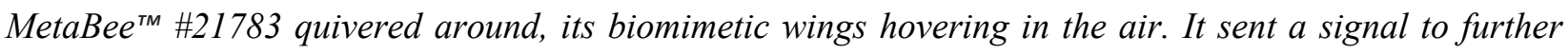
investigate the site to 27 other MetaBees ${ }^{\text {TM }}$ in the same hive, as well as sending a minor alert to its nearby military base. In the distance, fifteen feet beyond MetaBee ${ }^{T M}$ \#21783, there was movement. A human figure was heading the opposite way from MetaBee $e^{T M}$ \#21783's base. The MetaBee ${ }^{T M}$ class of drones was designed to only focus on triggered leaves; other models that specialized in enemy detection surveyed the forest for intruding animals and human forms. MetaBee ${ }^{T M}$ \#21783 made no note of this figure.

Bzzzzzzzz. Do you understand? I think you do. Invasive species and invasive genes. The forest teemed with life of different genres and the promise of genetic and computer codes yet to come. The canopy twisted as carbon levels increased in the air. MetaBee ${ }^{T M}$ \#21783 and its kin flew about, hummingbird wings on insect bodies. MetaBee ${ }^{T M}$ \#21783 turned to the right, flying a few feet towards another patch of spinach. Only one leaf was alight (perhaps it was a malfunction, a virus, or had been trampled by a deer). MetaBee ${ }^{\text {TM }}$ \#21783's battery was $73 \%$ percent full and there was still more nanobionic spinach to survey, information to be harvested. Was that a light in the distance? Seven other MetaBees ${ }^{\text {TM }}$ joined in.

Sam rubbed his knees, still sore from the fall, and started to head towards the scramble. He looked back towards the weeds he had fallen in, dull beneath the canopy, and remembered a viral meme from a few years ago about plants emailing. Everybody online joked about their ficuses and cacti sending messages to each other or hacking into their social media. Sam chuckled and pulled out his phone to check if he got any texts and to take another look at the map. No service and only $15 \%$ battery left. No signal for the plants either, he thought, as he hoisted himself over a boulder.

In the distance, a few dozen feet from Sam's head, a handful of pebbles bounced down the rocks. Three silhouettes stretched above: one long and wide, the other two small. Someone else had wandered off the path: Two kneeling figures and one standing tall, a parent and two young children? Sam thought of warning them, but of what he couldn't decide - the strange feeling he had in the spinach patch, shimmers in the air, something beyond the visible that escaped his eyes and tongue - and he didn't want to scare them either. They started heading down, the larger figure first who, when no longer backlit, was a man in his early 40s with wide shoulders and the first hint of a belly, helping two kids down.

"Beautiful day, isn't it?"

"Sure- how much further back to the trail?"

"Only ten minutes or so - keep going up then make a right at the cairn. How's the swimming down there? I read online that there was a swimming hole, and we could hear the trickle." 
“Oh, I didn’t make it in.”

Sam hurried away, making it back towards the trail. It remained crowded but so too was the forest itselfthe inescapable weekend march of city-dwellers, those buzzes in the air. He turned back once more and saw a few metallic flickers in the distance, flashing in and out of existence. Besides a faint whir, and one of the children's laughs, the forest was silent. Sam made it back to the path, and his phone service returned. Bzzzzz.

\section{Research Statement}

In this short speculation, I imagine a future forest that has been disturbed by invasive species, a changing climate, and engineered plant sensors. By staging this encounter between a wandering hiker, who never quite realizes that he is being watched, and MetaBee ${ }^{\mathrm{TM}} \# 21783$, a drone that watches over nanobionic spinach, I feel out the strangeness of this burgeoning mode of surveillance. In my own research, I term this operationalization of pollinator-plant relations, in which drones harvest information from engineered plants instead of pollen, a "vital informatics." That is to say, I argue that current military research into nanobionic and genetically engineered plants constitutes a living information science that integrates organic systems into data collection, storage, and processing. I primarily examine current projects funded by the Defense Advanced Research Projects Agency (DARPA) and ground my speculative fiction in DARPA's goal of producing nanobionic plants that can "detect the presence of certain chemicals, pathogens, radiation, and even electromagnetic signals" (Defense Advance Research Project Agency 2017).

I dialogue with existing work on autonomous drones and swarm intelligence, drawing on rich scholarship by Gregoire Chamayou (2015), Caroline Holmqvist (2013), Jeremy Packer and Joshua Reeves (2017), and Ian Shaw (2017), among others. In doing so, I look at the drone swarm as both that which tracks and surveils nanobionic plants and as a foil to plant intelligence. The mobility and plasticity of the swarm produce different notions of territory and nonhuman intelligence than plant nanobionics does, and I plumb this difference in my story, which contains both information-processing plants and insectoid drones. This is also manifest in the formal elements of the story and how the MetaBee narrative cuts through Sam's, revealing a whole loop of actions in which the human does not exist.

\section{References}

Chamayou, Grégoire. 2015. Drone Theory. London: Penguin Books.

Defense Advance Research Project Agency. 2017. Nature's Silent Sentinels Could Help Detect Security Threats. Legistorm, November 17. https:/www.legistorm.com/stormfeed/view_rss/1129219/organization/93578/title/natures-silent-sentinelscould-help-detect-security-threats.html [accessed October 15, 2021].

Holmqvist, Caroline. 2013. Undoing War: War Ontologies and the Materiality of Drone Warfare. Millennium 41 (3): 535-552.

Packer, Jeremy, and Joshua Reeves. 2017. Taking People Out: Drones, Media/Weapons, and the Coming Humanectomy. In Life in the Age of Drone Warfare, edited by Caren Kaplan and Lisa Parks, 261-281. Durham, NC: Duke University Press.

Shaw, Ian GR. Robot Wars: US Empire and Geopolitics in the Robotic Age. Security Dialogue 48 (5): 451-470. 